\title{
Stroke-induced immunosuppression and poststroke infection
}

\author{
Kaibin Shi, ${ }^{1,2}$ Kristofer Wood, ${ }^{2}$ Fu-Dong Shi, ${ }^{1,2}$ Xiaoying Wang, ${ }^{3}$ Qiang Liu ${ }^{1,2}$
}

To cite: Shi K, Wood K, Shi F-D, et al. Stroke-induced immunosuppression and poststroke infection. Stroke and Vascular Neurology 2018;3: e000123. doi:10.1136/svn2017-000123

Received 4 November 2017 Revised 3 December 2017 Accepted 11 December 2017 Published Online First 12 January 2018

\section{Check for updates}

${ }^{1}$ Departments of Neurology, Tianjin Neurological Institute, Tianjin Medical University General Hospital, Tianjin, China ${ }^{2}$ Departments of Neurology, Barrow Neurological Institute, St. Joseph's Hospital and Medical Center, Phoenix, Arizona, USA

${ }^{3}$ Departments of Neurology and Radiology, Neuroprotection Research Laboratory,

Massachusetts General Hospital, Neuroscience Program, Harvard Medical School, Boston, Massachusetts, USA

Correspondence to Dr Qiang Liu, Departments of Neurology Tianjin Neurological Institute, Tianjin Medical University General Hospital Tianjin China; qliu.asu@gmail.com

\section{ABSTRACT}

Infections occur commonly after stroke and are strongly associated with an unfavourable functional outcome of these patients. Approaches for effective management of poststroke infection remain scarce, presenting an urgent need for preventive anti-infection strategies for patients who have suffered a stroke. Emerging evidence indicates that stroke impairs systemic immune responses and increases the susceptibility to infections, suggesting that the modification of impaired immune defence could be beneficial. In this review, we summarised previous attempts to prevent poststroke infections using prophylactic antibiotics and the current understanding of stroke-induced immunosuppression. Further elucidation of the immune mechanisms of stroke will pave the way to tailored design of new treatment to combat poststroke infection via modifying the immune system.

\section{INTRODUCTION}

Infectious complications, pneumonia, urinary tract infections and infections in other organ systems, are common in patients with stroke with an incidence of $\sim 30 \% .{ }^{1-3}$ Poststroke infection is associated with about $20 \%$ of the deaths and related to considerable morbidity in stroke survivors. ${ }^{14-6}$ Given the well known detrimental effects of stroke-associated infection, effective management is critical. Antibiotics are the traditional approach used to manage infections, however, the recently completed clinical trials haven't demonstrated significant benefit of prophylactic antibiotics, ${ }^{7-10}$ presenting an urgent need to better understand the pathogenesis of stroke-associated infection and identify viable approaches to combat infectious complications. The inhibition of immunity after stroke has been recognised as a key contributor to infection in patients with stroke. Our increasing knowledge on stroke-induced immunosuppression poses an opportunity to boost immune defence and restrict poststroke infection. In this review, by summarising previous studies regarding attempts to manage poststroke infections and mechanisms of stroke-induced immunosuppression, we aim to provide insight into the basis of stroke-induced immunosuppression and propose new modalities to restore host immune defence after stroke.

\section{Prophylactic antibiotic treatment}

Studies in animal models of ischaemic stroke have demonstrated that preventive treatment with antibiotics reduces the incidence of infections, and improves mortality and neurological function. ${ }^{9}$ Based on these encouraging findings, a series of clinical trials that tested the safety and efficacy of prophylactic use of antibiotics in patients with stroke have been conducted (table 1). Among these 15 clinical studies, patient inclusion, stroke types, antibiotics selection and treatment duration differ from each other. The majority of these studies treated patients with broad-spectrum antibiotics to cover the most common causative bacteria of pneumonia and urinary tract infections, except for three studies that tested the neuroprotective effects of minocycline, which has inadequate bacterial coverage for patients with stroke; the infection results were not reported in these studies as well. ${ }^{11-13} \mathrm{~A}$ meta-analysis of a portion of these studies concluded that preventive treatment with antibiotics could reduce infection rates, but failed to reduce mortality and improve functional outcomes. ${ }^{14}$ This observation resembles findings in two recently completed phase III trials. ${ }^{78}$ Results from the Preventive Antibiotics in Stroke Study (PASS), which included 2358 patients from 30 Dutch centres, show that preventive antibiotic treatment after stroke was able to reduce poststroke infections, but did not improve functional outcomes at 3 months. ${ }^{8}$ The other phase III trial, testing prophylactic antibiotics after acute stroke for reducing pneumonia in patients with dysphagia (STROKE-INF), enrolled 1217 patients from 48 stroke units in the UK; it reported that prophylactic antibiotics did not reduce the frequency of pneumonia within 14 days after stroke onset, either as defined by algorithm or diagnosed by a physician. The secondary end point analyses showed that prophylactic antibiotics did not improve functional recovery at 3 months or mortality. ${ }^{7}$

Although the PASS and STROKE-IFN studies are different in many aspects, such as treatment time window, antibiotics selection 


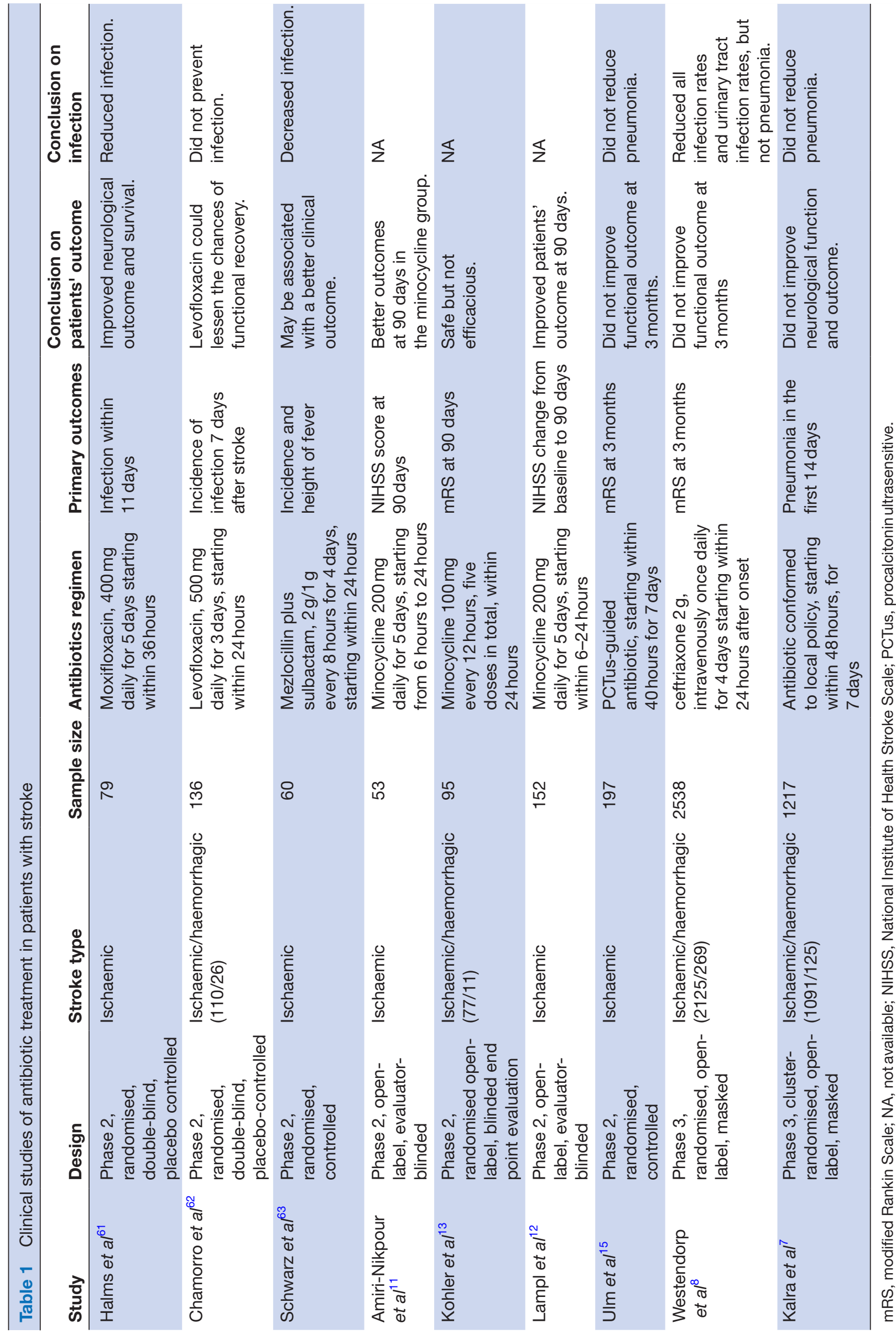


and patient inclusion criteria, the results of the two studies are highly consistent, that is, the treatment regimens of both studies failed to reduce the rate of pneumonia. Additionally, a recent study which tested antibiotic treatment in patients selected by the ultrasensitive procalcitonin test did not find a reduction of pneumonia in antibiotic-treated patients either. ${ }^{15}$ Therefore, since the antibiotic selection and treatment time window in these studies cannot prevent poststroke pneumonia, a possible explanation is that stroke-associated pneumonia might partly be a pneumonitis with more sterile components. ${ }^{16}$ In light of this speculation, the pathophysiological changes in the lung poststroke warrant further investigations for possible identification of new treatment strategies.

Although these clinical studies indicated that several antibiotics in different patients with stroke are safe, limitations regarding the selection of antibiotics for patients with stroke were also noted. For example, some antibiotics have neurotoxic effects and can worsen outcome. A preclinical study found that enrofloxacin (a fluoroquinolone antibiotic) treatment from day 1 to day 7 in rats undergoing middle cerebral artery occlusion, an ischaemic stroke model, worsened outcomes at 1 month. ${ }^{17}$ In this context, antibiotics that have neuroprotective properties should be considered in priority, like minocycline ${ }^{12} 18$ and ceftriaxone. ${ }^{19}$ However, the benefit of ceftriaxone was not demonstrated in PASS, which yielded to the secondary consideration of antibiotics choice, that is, whether broad-spectrum antibiotics are suitable for intervention in patients with stroke. Exposure to these broad-spectrum antibiotics may cause dysregulation of normal flora in the body, which might influence the stroke outcome, as suggested by a recent animal study in which broad-spectrum antibiotic treatment caused depletion of mice intestinal flora, worsening the outcome of stroke..$^{20}$ Therefore, the selection of antibiotics for patients with stroke must comprehensively consider the benefits as well as secondary adverse effects of the treatment.

As a severe type of stroke, intracerebral haemorrhage (ICH) accounts for about $10 \%-15 \%$ of all stroke types and is associated with high mortality and morbidity. ${ }^{21}{ }^{22}$ Infection is also a common and important complication in patients with ICH, and it can influence neurological function in the acute phase as well as long-term recovery. ${ }^{523}$ The reported infection rates in patients with ICH are similar to those with acute ischaemic stroke (AIS), about $30 \%$ of all patients, with higher rates in more severe patients admitted to an intensive care unit. ${ }^{24}{ }^{25}$ Currently, studies that have specifically tested antibiotic treatment in patients with ICH are still lacking. However, four of the published studies mentioned above (table 1) also recruited patients diagnosed with ICH. Two studies included only 26 and 11 patients with ICH, respectively, and thus are not suitable for subgroup analysis. In PASS, 269 patients with ICH were enrolled; subgroup analysis indicated that preventive ceftriaxone does not improve outcome in these patients either, however, whether or not preventive ceftriaxone was able to reduce the rate of pneumonia post ICH was not reported. In the STROKE-IFN Study, 125 patients with ICH were included; subgroup analysis indicated that prophylactic antibiotic treatment might reduce the rate of pneumonia in patients with ICH within 14 days after stroke, a noteworthy finding that warrants further confirmation in future studies with larger sample sizes.

Overall, for patients with AIS, prophylactic antibiotic treatment can reduce the rates of both total and urinary tract infections, but no such benefit was seen for stroke-associated pneumonia. In addition, preventive antibiotic treatment does not improve the outcome in patients. Hence, these findings do not support the use of antibiotics in a preventive manner. Preclinical and clinical evidence for the use of antibiotics in patients with ICH requires further enlightenment.

\section{Stroke-induced immunosuppression}

The immune system and nervous system crosstalk with each other via multiple facets to maintain the homoeostasis of both systems under physiology conditions. ${ }^{26-30}$ Severe brain injuries, including stroke, can interrupt such balance and lead to a series of changes in both systems. ${ }^{31}$ Brain injury after an ischaemic or haemorrhagic stroke leads to the activation and infiltration of inflammatory cells into the brain. ${ }^{32-35}$ While poststroke inflammation may contribute to the clearance of tissue debris and tissue repair, most published literature indicates that inflammation in the brain during the acute phase of stroke promotes the expansion of stroke lesions and worsens neurodeficits. ${ }^{36-38}$ Further, inhibition of the immune response in the brain during the acute phase can limit the extent of stroke injury. ${ }^{33} 34{ }^{38-42}$ Conversely, the injured brain can reshape peripheral immunity and transition the functional status of the peripheral immune system from competence to suppression after the acute phase of stroke, as manifested by lymphopenia, decreased levels of inflammatory cytokines, monocyte and lymphocyte dysfunction, and atrophy of secondary lymphoid organs. ${ }^{31} 364344$ Brain lesion size has been considered as an independent risk factor of poststroke immunosuppression and infectious complications. ${ }^{45}$ It has been postulated that stroke-induced immunosuppression might be an adaptive response to acute brain injury, because systemic immunosuppression may limit the overwhelming inflammation in the brain or reduce the occurrence of autoimmune reactions against neuroantigens. ${ }^{46}{ }^{47}$ However, a protective role of immunosuppression after stroke, if any, is uncertain and remains to be defined.

A consequence of immunosuppression has been linked to the increased risk of infection after stroke onset. ${ }^{47}$ An established concept is that brain-derived neurogenic innervations are in control of systemic immunity. In the context of stroke, brain injury-induced activation of neurogenic pathways, including the sympathetic innervation, hypothalamic-pituitary-adrenal (HPA) axis and parasympathetic innervation work together 
to influence the magnitude and intensity of systemic immune response. ${ }^{43} 48$ The central mediators of these pathways include norepinephrine, acetylcholine and glucocorticoid hormones. ${ }^{27}{ }^{31}$ Receptors of these molecules are broadly expressed in immune cells. ${ }^{43} 49$ Activation of the sympathetic nervous system induces the release of catecholamines from sympathetic nerve terminals. Transient increase of catecholamine release often leads to increased blood immune cells by mobilising them from peripheral reservoirs such as the spleen; however, stroke induces a prolonged elevation of circulating catecholamines, ${ }^{44}$ which promotes the apoptosis of immune cells and leads to a decrease of peripheral immune cells and a bias towards T helper cell 2 (Th2) immune response. ${ }^{50}{ }^{51}$ Glucocorticoids, key mediators for HPA axis function, have antiproliferative effects to induce apoptosis of immune cells. ${ }^{52}$ Additionally, glucocorticoids can promote the production of anti-inflammatory cytokines like transforming growth factor $\beta$ (TGF- $\beta$ ) ${ }^{53}$ while inhibiting the production of proinflammatory cytokines, such as interleukin (IL) 1, IL-8 and umor necrosis factor $\alpha(\mathrm{TNF}-\alpha){ }^{54}$ The anti-inflammatory effects of cholinergic pathways mediated by acetylcholine was recently uncovered; macrophages can be quickly inhibited when exposed to acetylcholine, with decreased secretion of proinflammatory cytokines like TNF- $\alpha$, IL- $1 \beta$ and IL- $18 .{ }^{55}$
In addition to peripheral immunosuppression, stroke also suppresses immunity in the ischaemic brain. Ischaemic neurons can secrete several neurotransmitters like acetylcholine (Ach), glutamate, serotonin, and so on, which can directly interact with the receptors of peripheral infiltrated lymphocytes and modulate their functional status. ${ }^{43} \mathrm{~A}$ model of stroke-induced immunosuppression is illustrated in figure 1 using natural killer (NK) cells as an example. The identification of the mechanisms underlying stroke-induced immunosuppression offers the possibility of the use of immune modulation as a novel approach to boost host defence and combat poststroke infections.

\section{Potential therapies to combat stroke-associated infection}

Animal experiments demonstrated that pharmacological blockade of the sympathetic pathway or HPA axis by $\beta$-blockers or glucocorticoid receptor antagonists could reduce stroke-induced immune dysfunction and poststroke infection to improve animals' functional outcome (table 2) ${ }^{48}{ }^{56}$ However, the clinical relevance remains unclear (table 3). A small prospective study indicated that $\beta$-blocker use is associated with less severe stroke at presentation, with lower thrombin, haemoglobin $\mathrm{A}_{1} \mathrm{C}$ levels, and erythrocyte sedimentation rate. ${ }^{57}$ Another retrospective analysis of 841 patients with ischaemic stroke, $10.6 \%$

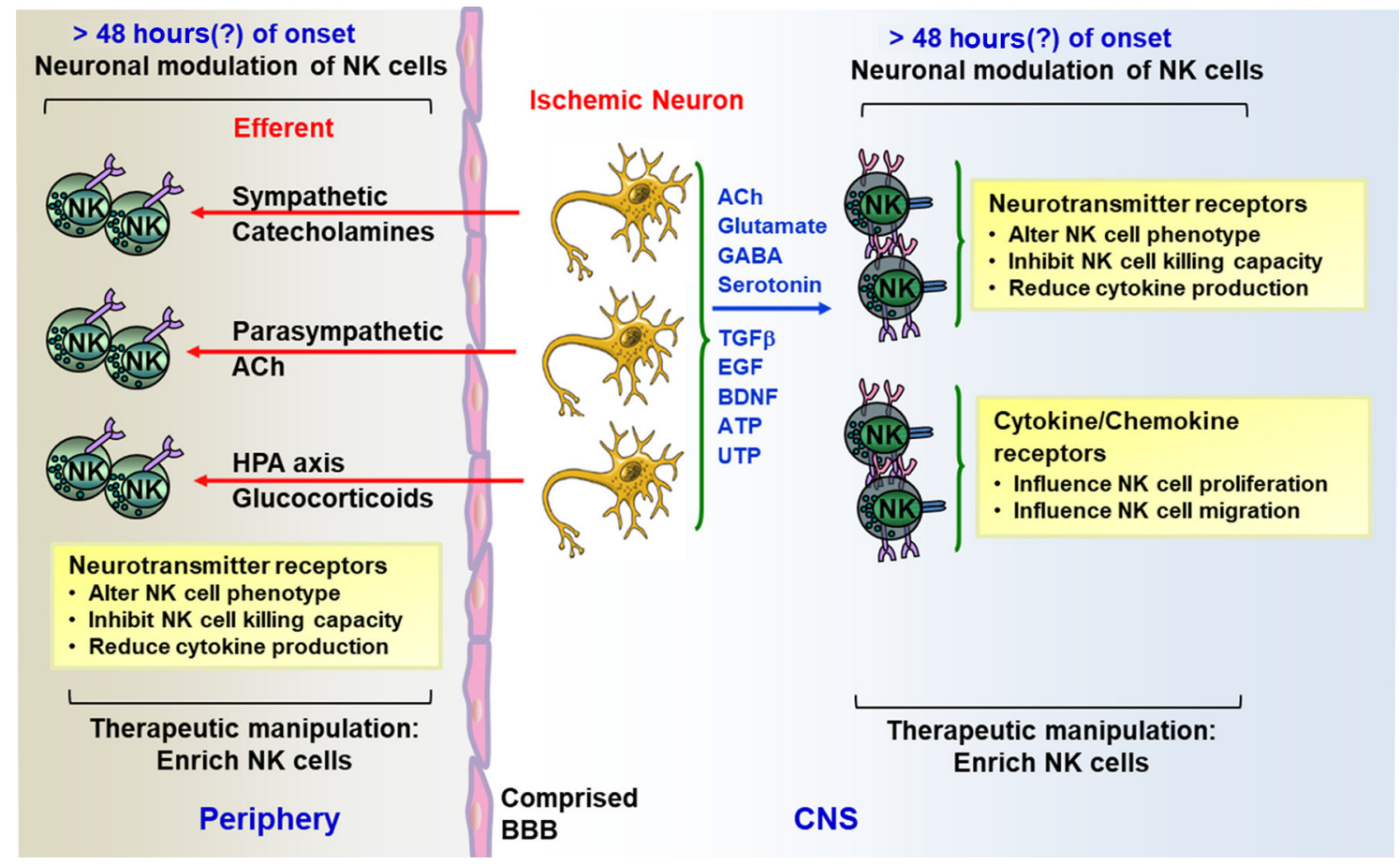

Figure 1 Schematic diagram of mechanisms of stroke-induced immunosuppression with NK cells as an example. In the early stages of stroke ( $<24$ hours), ischaemic neuron-recruited NK cells are swiftly mobilised into ischaemic areas, where they promote neuronal death (not shown in figure). ${ }^{34}$ Subsequently ( $>48$ hours?), ischaemic neuron-derived signals can turn off NK cells that express neurotransmitter receptors. At the peripheral level, ischaemic brain injury influences the sympathetic, parasympathetic (vagus nerve) and/or hypothalamic-pituitary-adrenal (HPA) axis systems that suppress NK cell-mediated immunity. Differences in the spectrum of neurogenic innervations, immune cell subsets and soluble mediators in the CNS versus the periphery may differentially affect ${ }_{N K}$ cell deficiency in these two compartments. BBB, blood brain barrier; BDNF, brainderived neurotrophic factor; CNS, central nervous system; EGF, epithelial growth factor; GABA, gamma-aminobutyric acid; NK, natural killer; UTP, uridine triphosphate. 


\begin{tabular}{|c|c|c|}
\hline Objects & Approaches & Conclusions \\
\hline \multirow[t]{2}{*}{$\begin{array}{l}\text { Mouse, } 60 \mathrm{~min} \\
\text { MCAO }\end{array}$} & $\beta$-blocker, propranolol & $\begin{array}{l}\text { Prevented bacterial infections post-MCAO and reduced mice } \\
\text { mortality. }\end{array}$ \\
\hline & HPA blocker, RU486 & Did not prevent bacterial infections after MCAO. \\
\hline \multirow{2}{*}{$\begin{array}{l}\text { Mouse, } 60 \mathrm{~min} \\
\text { MCAO }\end{array}$} & $\beta 2$-adrenergic receptor blocker & Preserved IFN- $\gamma$ production by lymphocytes after stroke. \\
\hline & HPA blocker, RU486 & Prevented poststroke lymphopenia. \\
\hline \multirow{2}{*}{$\begin{array}{l}\text { Rat, permanent } \\
\text { MCAO }\end{array}$} & $\beta$-blocker, propranolol & No effects on spleen size and stroke outcome. \\
\hline & $\alpha 1$ receptor blocker, prazosin & $\begin{array}{l}\text { Prevented the reduction in spleen size; no effect on infarct } \\
\text { volume. }\end{array}$ \\
\hline $\begin{array}{l}\text { Mouse, } 60 \mathrm{~min} \\
\text { MCAO }\end{array}$ & $\beta$-blocker, propranolol & $\begin{array}{l}\text { Preserved iNKT cell function and reduced poststroke } \\
\text { infection. }\end{array}$ \\
\hline $\begin{array}{l}\text { Mouse, } 60 \mathrm{~min} \\
\text { MCAO }\end{array}$ & $\begin{array}{l}\beta \text {-blocker, propranolol } \\
\text { HPA blocker, RU486 }\end{array}$ & $\begin{array}{l}\text { Propranolol and RU486 synergistically inhibited } \\
\text { immunosuppression poststroke, prevented infection and } \\
\text { improved the functional outcome of mice. }\end{array}$ \\
\hline
\end{tabular}

2D2 mice, myelin oligodendrocyte glycoprotein (MOG) T cell receptor transgenic mice; HPA, hypothalamic-pituitary-adrenal axis; IFN $-\gamma$, interferon- $\gamma$; iNKT, invariant NKT; MCAO, middle cerebral artery occlusion; WT, wild type.

of whom received $\beta$-blockers during hospitalisation, also implied that $\beta$-blockers might be neuroprotective, as the use of $\beta$-blockers was associated with reduced risk of early death; however, this association no longer exists when excluding mortality from cardiovascular causes. ${ }^{58}$ Of interest, a study that included 625 patients, among which 553 patients were admitted with AIS and 72 with ICH, reported that $\beta$-blocker exposure, defined as receiving $\beta$-blockers prior to stroke and continued treatment during hospitalisation, did not reduce the risk of stroke-associated pneumonia, but reduced urinary tract infection rates. In addition, patients receiving $\beta$-blocker therapy showed a higher 30-day mortality than those without exposure to $\beta$-blockers. ${ }^{59}$ However, a recent non-randomised study of 5212 patients with ischaemic stroke suggested that, either treatment with $\beta$-blockers before stroke onset or starting treatment after stroke onset was associated with reduced frequency of pneumonia, and $\beta$-blocker exposure during stroke was associated with reduced mortality. ${ }^{60}$ In PASS, 885 patients received $\beta$-blockers, but subgroup analysis of this factor was not reported and further analysis regarding the safety and efficacy of such therapy on stroke outcome, as well as in combination with preventive antibiotic treatment, is awaited. Thus, the safety of systemic $\beta$-blockade remains controversial in the context of patients with stroke, and randomised trials may be warranted for further determination. In particular, the adverse effects of systemic inhibition of sympathetic input by $\beta$-blockers might counteract its protective effect of immune modulation, which warrants further verification. Ultimately, developing selective blockers of lymphocytic $\beta$-adrenergic receptors or downstream signalling pathways might avoid the adverse systemic impacts.

Boosting peripheral immunity might serve as another viable approach to countering poststroke infections and avoiding the systemic effects of neurogenic innervations. Preclinical data have demonstrated that adoptive transfer T or NK cells, as well as injection of IFN- $\gamma$ to animals during the subacute stage of ischaemic stroke ( $>24$ hours) reduces the rate of pneumonia and improves the outcome. ${ }^{436}$ Additionally, treating animals subjected to brain ischaemia with $\alpha$-galactosylceramide, a specific activator that can promote proinflammatory cytokines production by the invariant natural killer T cell (NKT) (iNKT) cell, is able to reduce stroke-associated infections. ${ }^{48}$ Currently, the safety and efficacy of this approach has not been tested in clinical trials. Nevertheless, before translation to the clinic, the contribution of different cell types and cytokines to restrict stroke-associated infections require further investigations.

\section{CONCLUSIONS}

Poststroke infections, especially pneumonia, still present challenges for clinical management of patients with stroke. Preventive administration of antibiotics can somewhat reduce infection rates but not pneumonia, and cannot improve the outcome and survival in patients with stroke; thus, the use of antibiotics in a prophylactic manner remains controversial. Modulation of the 
Table 3 Clinical use of $\beta$-blockers in patients with stroke

\begin{tabular}{|c|c|c|c|c|c|}
\hline Study & Design & Stroke type & $\begin{array}{l}\text { Sample size } \\
\text { and group }\end{array}$ & End points & Conclusions \\
\hline Raedt et $a l^{66}$ & $\begin{array}{l}\text { Subgroup analysis } \\
\text { of two lubeluzole } \\
\text { studies }\end{array}$ & Ischaemic & $\begin{array}{l}1375, \text { with } \\
264 \text { receiving } \\
\beta \text {-blockers }\end{array}$ & $\begin{array}{l}\text { Poor functional } \\
\text { outcome }(\mathrm{mRS}>3) \text { at } \\
3 \text { months }\end{array}$ & $\begin{array}{l}\text { Use of } \beta \text {-blockers does not } \\
\text { appear to influence stroke } \\
\text { severity and functional } \\
\text { outcome at } 3 \text { months. }\end{array}$ \\
\hline Laowattana et $\left.a\right|^{57}$ & Prospective & Ischaemic & $\begin{array}{l}111, \text { with } 22 \\
\text { treated with } \\
\beta \text {-blockers }\end{array}$ & $\begin{array}{l}\text { Stroke severity } \\
\text { on presentation } \\
\text { gauged by Canadian } \\
\text { Neurologic Scale } \\
\text { (CanNS) }\end{array}$ & $\begin{array}{l}\text { Use of } \beta \text {-blocker is } \\
\text { associated with less severe } \\
\text { stroke on presentation and } \\
\text { may be cerebroprotective. }\end{array}$ \\
\hline
\end{tabular}

\begin{tabular}{|c|c|c|c|c|c|}
\hline $\begin{array}{l}\text { Dziedzic } \\
\text { et }\left.a\right|^{58}\end{array}$ & Retrospective & Ischaemic & $\begin{array}{l}841, \text { with } 88 \\
\text { treated with } \\
\beta \text {-blockers }\end{array}$ & 30-day case fatality & $\begin{array}{l}\beta \text {-blocker use was } \\
\text { associated with reduced risk } \\
\text { of early death. }\end{array}$ \\
\hline
\end{tabular}

$\begin{array}{lllll}\text { Maier et al } & \text { Historical cohort } & \text { Ischaemic/ } & 625, \text { with } 301 & \text { Pneumonia, urinary } \\ & \text { study } & \text { Haemorrhagic } & \text { treated with } & \text { tract infections and } \\ & 553 / 72 & \beta \text {-blockers } & \text { death }\end{array}$

$\beta$-blocker therapy did not reduce the risk for poststroke pneumonia, but significantly reduced the risk for urinary tract infections; patients with $\beta$-blocker therapy showed higher 30day mortality.

\begin{tabular}{|c|c|c|c|c|c|}
\hline Sykora et al ${ }^{60}$ & Non-randomised & Ischaemic & $\begin{array}{l}5212 \text {, with } \\
1155 \text { treated } \\
\text { with } \beta \text {-blockers } \\
\text { before stroke } \\
\text { and } 244 \\
\text { started in } \\
\text { acute phase }\end{array}$ & $\begin{array}{l}\text { Mortality, functional } \\
\text { outcome (mRS), } \\
\text { occurrence of } \\
\text { pneumonia }\end{array}$ & $\begin{array}{l}\beta \text {-blocker therapy was } \\
\text { associated with reduced } \\
\text { pneumonia frequency; } \\
\text { treatment started in acute } \\
\text { phase of stroke was } \\
\text { associated with reduced } \\
\text { mortality; no association } \\
\text { with functional outcome. }\end{array}$ \\
\hline
\end{tabular}

mRS, modified Rankin Scale.

immune system via neurogenic pathways may serve as a potential therapy for patients with stroke. Reported clinical studies indicated a discrepancy in the responsiveness to treatment between poststroke pneumonia and other infections, such as urinary tract infection. This suggests that poststroke pneumonia could be more refractory to treatment than other types of infections. Considering the currently limited treatment options for stroke, future design of stroke treatment is imperative to mitigate immunosuppression, and thus to decrease the risk of infectious complications after stroke.

Contributors QL, F-DS and XW formulated the concept, KS reviewed the articles and drafted the manuscript, KW contributed to discussion and editing the manuscript.

Funding This study was supported in part by the National Basic Research Program of China, grant 2013CB966900; National Science Foundation of China, grant 81230028, 81301044, 81471535; American Heart Association, grant 16SDG27250236; National Institutes of Health, grant R01NS092713; National Multiple Sclerosis Society, grant RG-1507-05318.

Competing interests None declared.

Provenance and peer review Commissioned; externally peer reviewed. Data sharing statement № additional data are available.

Open Access This is an Open Access article distributed in accordance with the Creative Commons Attribution Non Commercial (CC BY-NC 4.0) license, which permits others to distribute, remix, adapt, build upon this work non-commercially, and license their derivative works on different terms, provided the original work is properly cited and the use is non-commercial. See: http://creativecommons.org/ licenses/by-nc/4.0/

(C) Article author(s) (or their employer(s) unless otherwise stated in the text of the article) 2018. All rights reserved. No commercial use is permitted unless otherwise expressly granted.

\section{REFERENCES}

1. Westendorp WF, Nederkoorn PJ, Vermeij JD, et al. Post-stroke infection: a systematic review and meta-analysis. BMC Neurol 2011;11:110.

2. Gong S, Zhou Z, Zhou M, et al. Validation of risk scoring models for predicting stroke-associated pneumonia in patients with ischaemic stroke. Stroke Vasc Neurol 2016;1:122-6.

3. Zheng $\mathrm{H}, \mathrm{Cao} \mathrm{N}$, Yin $\mathrm{Y}$, et al. Stroke recovery and rehabilitation in Vasc Neurol 2017;2:222-9.

4. Giede-Jeppe A, Bobinger T, Gerner ST, et al. Lymphocytopenia Is spontaneous intracerebral hemorrhage. Stroke 2016;47:1239-46.

5. Lord AS, Lewis A, Czeisler B, et al. Majority of 30-day readmissions after intracerebral hemorrhage are related to infections. Stroke 2016;47:1768-71.

6. Kwan J, Pickering RM, Kunkel D, et al. Impact of stroke-associated infection on long-term survival: a cohort study. J Neurol Neurosurg Psychiatry 2013;84:297-304.

7. Kalra L, Irshad S, Hodsoll J, et al. Prophylactic antibiotics after acute stroke for reducing pneumonia in patients with dysphagia (STROKE-INF): a prospective, cluster-randomised, open-label, 2016: a year in review of basic science and clinical science. Stroke an independent predictor of unfavorable functional outcome in 
masked endpoint, controlled clinical trial. Lancet 2015;386:1835-44.

8. Westendorp WF, Vermeij JD, Zock E, et al. The Preventive Antibiotics in Stroke Study (PASS): a pragmatic randomised open-label masked endpoint clinical trial. Lancet 2015;385:1519-26.

9. Hetze S, Engel O, Römer C, et al. Superiority of preventive antibiotic treatment compared with standard treatment of poststroke pneumonia in experimental stroke: a bed to bench approach. $J$ Cereb Blood Flow Metab 2013;33:846-54.

10. Ormseth $\mathrm{CH}$, Sheth $\mathrm{KN}$, Saver JL, et al. The American Heart Association's Get With the Guidelines (GWTG)-stroke development and impact on stroke care. Stroke Vasc Neurol 2017;2:94-105.

11. Amiri-Nikpour MR, Nazarbaghi S, Hamdi-Holasou M, et al. An openlabel evaluator-blinded clinical study of minocycline neuroprotection in ischemic stroke: gender-dependent effect. Acta Neurol Scand 2015;131:45-50.

12. Lampl Y, Boaz M, Gilad R, et al. Minocycline treatment in acute stroke: an open-label, evaluator-blinded study. Neurology 2007;69:1404-10.

13. Kohler E, Prentice DA, Bates TR, et al. Intravenous minocycline in acute stroke: a randomized, controlled pilot study and meta-analysis. Stroke 2013;44:2493-9.

14. Westendorp WF, Vermeij JD, Vermeij F, et al. Antibiotic therapy for preventing infections in patients with acute stroke. Cochrane Database Syst Rev 2012;1:CD008530.

15. Ulm L, Hoffmann S, Nabavi D, et al. The randomized controlled STRAWINSKI trial: procalcitonin-guided antibiotic therapy after stroke. Front Neurol 2017;8:153.

16. Marik PE. Aspiration pneumonitis and aspiration pneumonia. N Engl J Med 2001;344:665-71.

17. Zierath D, Kunze A, Fecteau L, et al. Effect of antibiotic class on stroke outcome. Stroke 2015;46:2287-92.

18. Soliman S, Ishrat T, Fouda AY, et al. Sequential therapy with minocycline and candesartan improves long-term recovery after experimental stroke. Trans/ Stroke Res 2015;6:309-22.

19. Thöne-Reineke C, Neumann C, Namsolleck P, et al. The beta-lactam antibiotic, ceftriaxone, dramatically improves survival, increases glutamate uptake and induces neurotrophins in stroke. $J$ Hypertens 2008;26:2426-35.

20. Winek K, Engel O, Koduah P, et al. Depletion of cultivatable gut microbiota by broad-spectrum antibiotic pretreatment worsens outcome after murine stroke. Stroke 2016;47:1354-63.

21. Qureshi Al, Mendelow AD, Hanley DF. Intracerebral haemorrhage. Lancet 2009;373:1632-44.

22. Dastur CK, Yu W. Current management of spontaneous intracerebral haemorrhage. Stroke Vasc Neurol 2017;2:21-9.

23. Lord AS, Langefeld CD, Sekar $P$, et al. Infection after intracerebral hemorrhage: risk factors and association with outcomes in the ethnic/racial variations of intracerebral hemorrhage study. Stroke 2014;45:3535-42.

24. Ohwaki K, Yano E, Nagashima H, et al. Impact of infection on length of intensive care unit stay after intracerebral hemorrhage. Neurocrit Care 2008;8:271-5.

25. Morotti A, Marini S, Jessel MJ, et al. Lymphopenia, infectious complications, and outcome in spontaneous intracerebral hemorrhage. Neurocrit Care 2017;26:160-6.

26. Liu $Q$, Sanai N, Jin WN, et al. Neural stem cells sustain natural killer cells that dictate recovery from brain inflammation. Nat Neurosci 2016;19:243-52.

27. Chavan SS, Pavlov VA, Tracey KJ. Mechanisms and therapeutic relevance of neuro-immune communication. Immunity 2017;46:927-42.

28. Shi FD, Ljunggren HG, La Cava A, et al. Organ-specific features of natural killer cells. Nat Rev Immunol 2011;11:658-71.

29. Shi FD. Neuroinflammation. Neurosci Bull 2015;31:714-6.

30. Shi K, Wang Z, Liu Y, et al. CFHR1-modified neural stem cells ameliorated brain injury in a mouse model of neuromyelitis optica spectrum disorders. The Journal of Immunology 2016;197:3471-80.

31. Meisel C, Schwab JM, Prass K, et al. Central nervous system injury-induced immune deficiency syndrome. Nat Rev Neurosci 2005;6:775-86.

32. Li M, Li Z, Ren $\mathrm{H}$, et al. Colony stimulating factor 1 receptor inhibition eliminates microglia and attenuates brain injury after intracerebral hemorrhage. J Cereb Blood Flow Metab 2017;37:2383-95.

33. Li M, Li Z, Yao Y, et al. Astrocyte-derived interleukin-15 exacerbates ischemic brain injury via propagation of cellular immunity. Proc Nat Acad Sci U S A 2017;114:E396-E405.
34. Gan Y, Liu Q, Wu W, et al. Ischemic neurons recruit natural killer cells that accelerate brain infarction. Proc Natl Acad Sci U S A 2014;111:2704-9.

35. Zhang F, Yan C, Wei C, et al. Vinpocetine inhibits NF-кB-dependent inflammation in acute ischemic stroke patients. Trans/ Stroke Res 2017.

36. Fu Y, Liu Q, Anrather J, et al. Immune interventions in stroke. Nat Rev Neurol 2015;11:524-35.

37. Urday S, Kimberly WT, Beslow LA, et al. Targeting secondary injury in intracerebral haemorrhage-perihaematomal oedema. Nat Rev Neurol 2015;11:111-22.

38. Sun N, Shen $\mathrm{Y}$, Han W, et al. Selective sphingosine-1-phosphate receptor 1 modulation attenuates experimental intracerebral hemorrhage. Stroke 2016;47:1899-906.

39. $\mathrm{Fu} \mathrm{Y}$, Hao J, Zhang N, et al. Fingolimod for the treatment of intracerebral hemorrhage: a 2-arm proof-of-concept study. JAMA Neurol 2014;71:1092-101.

40. Zhu Z, Fu Y, Tian D, et al. Combination of the immune modulator fingolimod with alteplase in acute ischemic stroke: a pilot trial. Circulation 2015:132:1104-12.

41. Fu Y, Zhang N, Ren L, et al. Impact of an immune modulator fingolimod on acute ischemic stroke. Proc Natl Acad Sci U S A 2014:111:18315-20.

42. Yao Y, Miao W, Liu Z, et al. Dimethyl Fumarate and Monomethyl Fumarate Promote Post-Ischemic recovery in Mice. Trans/ Stroke Res 2016;7:535-47.

43. Liu Q, Jin WN, Liu Y, et al. Brain ischemia suppresses immunity in the periphery and brain via different neurogenic innervations. Immunity 2017;46:474-87.

44. Zhang J, Shi K, Li Z, et al. Organ- and cell-specific immune responses are associated with the outcomes of intracerebral hemorrhage. Faseb J 2017;32:fj.201700324R.

45. Hug A, Dalpke A, Wieczorek N, et al. Infarct volume is a major determiner of post-stroke immune cell function and susceptibility to infection. Stroke 2009;40:3226-32.

46. Römer $\mathrm{C}$, Engel $\mathrm{O}$, Winek $\mathrm{K}$, et al. Blocking stroke-induced immunodeficiency increases CNS antigen-specific autoreactivity but does not worsen functional outcome after experimental stroke. J Neurosci 2015;35:7777-94.

47. Dirnagl U, Klehmet J, Braun JS, et al. Stroke-induced immunodepression: experimental evidence and clinical relevance. Stroke 2007;38(2 Suppl):770-3

48. Wong $\mathrm{CH}$, Jenne $\mathrm{CN}$, Lee WY, et al. Functional innervation of hepatic iNKT cells is immunosuppressive following stroke. Science 2011;334:101-5

49. Felten DL, Felten SY, Bellinger DL, et al. Noradrenergic sympathetic neural interactions with the immune system: structure and function. Immunol Rev 1987;100:225-60.

50. Sanders VM, Baker RA, Ramer-Quinn DS, et al. Differential expression of the beta2-adrenergic receptor by Th1 and Th2 clones: implications for cytokine production and B cell help. J Immunol 1997:158:4200-10.

51. Panina-Bordignon P, Mazzeo D, Lucia PD, et al. Beta2-agonists prevent Th1 development by selective inhibition of interleukin 12. J Clin Invest 1997;100:1513-9.

52. Szabó C, Thiemermann C, Wu CC, et al. Attenuation of the induction of nitric oxide synthase by endogenous glucocorticoids accounts for endotoxin tolerance in vivo. Proc Natl Acad Sci U S A 1994;91:271-5.

53. Hodge S, Hodge G, Flower R, et al. Methyl-prednisolone upregulates monocyte interleukin-10 production in stimulated whole blood. Scand J Immunol 1999;49:548-53.

54. Barrat FJ, Cua DJ, Boonstra A, et al. In vitro generation of interleukin 10-producing regulatory CD4(+) T cells is induced by immunosuppressive drugs and inhibited by T helper type 1 (Th1)and Th2-inducing cytokines. J Exp Med 2002;195:603-16.

55. Borovikova LV, Ivanova S, Zhang M, et al. Vagus nerve stimulation attenuates the systemic inflammatory response to endotoxin. Nature 2000;405:458-62.

56. Prass K, Meisel C, Höflich C, et al. Stroke-induced immunodeficiency promotes spontaneous bacterial infections and is mediated by sympathetic activation reversal by poststroke T helper cell type 1-like immunostimulation. J Exp Med 2003;198:725-36.

57. Laowattana S, Oppenheimer SM. Protective effects of beta-blockers in cerebrovascular disease. Neurology 2007;68:509-14.

58. Dziedzic T, Slowik A, Pera J, et al. Beta-blockers reduce the risk of early death in ischemic stroke. J Neurol Sci 2007;252:53-6.

59. Maier IL, Karch A, Mikolajczyk R, et al. Effect of beta-blocker therapy on the risk of infections and death after acute stroke-a historical cohort study. PLoS One 2015;10:e0116836. 
60. Sykora M, Siarnik P, Diedler J, VISTA Acute Collaborators. $\beta$-blockers, pneumonia, and outcome after ischemic stroke: evidence from virtual international stroke trials archive. Stroke 2015;46:1269-74.

61. Harms H, Prass K, Meisel C, et al. Preventive antibacterial therapy in acute ischemic stroke: a randomized controlled trial. PLOS One 2008;3:e2158

62. Chamorro A, Horcajada JP, Obach V, et al. The early systemic prophylaxis of infection after stroke study: a randomized clinical trial. Stroke 2005;36:1495-500.

63. Schwarz S, Al-Shajlawi F, Sick C, et al. Effects of prophylactic antibiotic therapy with mezlocillin plus sulbactam on the incidence and height of fever after severe acute ischemic stroke: the Mannheim infection in stroke study (MISS). Stroke 2008;39:1220-7.

64. Mracsko E, Liesz A, Karcher S, et al. Differential effects of sympathetic nervous system and hypothalamic-pituitary-adrenal axis on systemic immune cells after severe experimental stroke. Brain Behav Immun 2014;41:200-9.

65. Ajmo CT, Collier LA, Leonardo CC, et al. Blockade of adrenoreceptors inhibits the splenic response to stroke. Exp Neurol 2009;218:47-55.

66. De Raedt S, Haentjens P, De Smedt A, et al. Pre-stroke use of betablockers does not affect ischaemic stroke severity and outcome. Eur J Neurol 2012;19:234-40. 